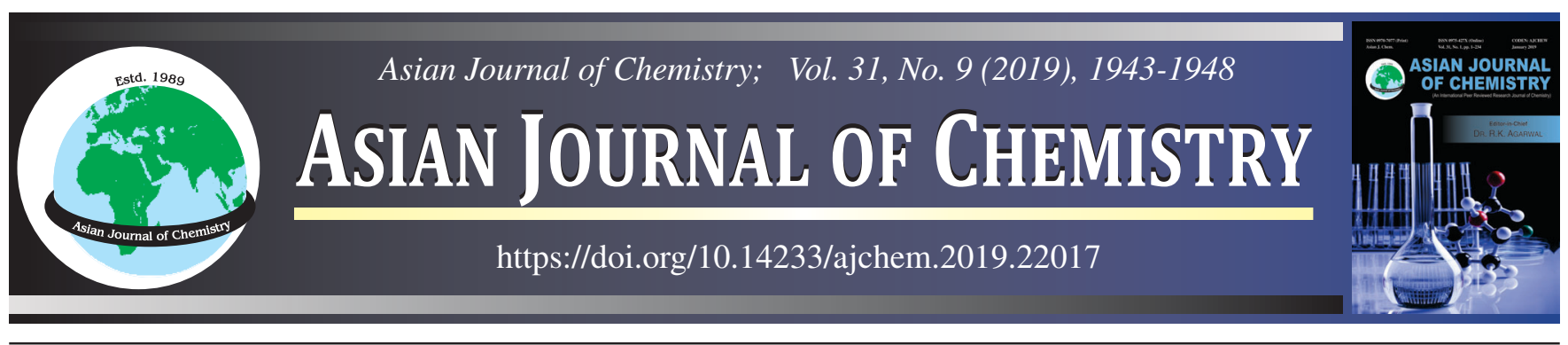

\title{
Chitosan Grafted Carbon Nanotubes Reinforced Vinyl Ester/UPE Blend Based Partially Bio-Nanocomposite
}

Priyabrata Mohanty ${ }^{1}$, Tapan Kumar Bastia ${ }^{1, *}$, Dibakar Behera $^{1}$ and Shivkumari Panda ${ }^{2}$

${ }^{1}$ Department of Chemistry, School of Applied Sciences, KIIT University, Bhubaneswar-751024, India

${ }^{2}$ Department of Chemistry, Udayanath Autonomous College of Science and Technology, Cuttack-754001, India

*Corresponding author: E-mail: drtkbastia@gmail.com

Received: 21 February 2019;

Accepted: 13 April 2019;

Published online: 31 July 2019;

AJC-19480

This work represents the preparation and characterization of some unique properties of vinyl ester (VE) and unsaturated polyester (UPE) blend based nanocomposites by introducing biopolymer chitosan grafted multi-walled carbon nanotubes (MWCNTs). Initially, surface grafting of MWCNTs with chitosan was performed by utilizing glutaraldehyde as a cross linking reagent through covalent deposition method and are successfully characterized by Fourier transform infrared spectroscopy (FTIR) and scanning electron microscopy(SEM).

Then 50:50 wt \% of vinyl ester and unsaturated polyester blend was prepared by simple sonication method. Three different specimens of VE/UPE/CS- $g$-MWCNTs nanocomposites were fabricated with addition of 1, 3 and 5 wt $\%$ of functionalized bionanofiller. Chitosan grafting of MWCNTs offered enhanced properties to the nanocomposites suggesting homogeneous distribution of the nanofiller in the matrix with minimum corrosion and swelling properties. $3 \mathrm{wt} \%$ of functionalized bionanofiller loading showed superior essential characteristics and after that the properties reduced may be due to the nucleating tendency of the nanofiller particles.

Keywords: Unsaturated polyester matrix, Vinyl ester, Blend based nanocomposite, Biopolymer chitosan grafted MWCNTs.

ᄂ _ _ - - - - - - - - - - - - - - - - - - - - - - - - - - - - - -

\section{INTRODUCTION}

Carbon based polymer composites have engrossed much more attention from the researchers and various industries because of the superior properties with remarkable applications $[1,2]$. Since the discovery of carbon nanotubes (CNT) in 1991, it has attracted the scientific community towards their outstanding mechanical, thermal and electrical [3-5] properties. In many aspects, it is considered as the dominating allotropy of carbon. However, it is a technical challenge for the modern scenario to prepare nanocomposites with high loading of multi-walled carbon nanotubes (MWCNTs) due to their poor solubility and nucleating tendency. So, to avoid such type of bottlenecks it is important to functionalize CNTs with other types of nonbiodegradable or biodegradable materials. Here chitosan is used as the novel unique material to functionalize these MWCNTs nanofiller. Chitosan (CS), a N-deacetylated derivative of chitin, consists of 2-amino-2-deoxy (1-4)- $\beta$-D-glucopyranose residue and is acquired from the deacetylation of chitin. It is widely available in nature, specifically in the shell of crustaceans, fishes and exoskeleton of insects. Due to the accomplished biocompatibility, biodegradability, easy availability and nontoxic [6-9] properties, it has been broadly used in various fields such as pharmaceutics, tissue engineering and as food additive and cosmetics [10-13]. So, here introduction of chitosan on the surface of MWCNTs offers a new approach to design a high performance based partially bionanocomposite materials with broad applicability.

Unsaturated polyesters (UPE) is a broad name in the field of thermosetting resin. It is used in a wide range of commercial products as plastics, fibers, composites and coating applications [14]. Use of this polymer has been increasing over the last four decades due to its relatively high specific strength, corrosion resistance, design flexibility and low density. Again, this unsaturated polyester is broadly used as commercial fibers, plastics, composites and coating applications [15]. The major utilization of this thermoset resin is successfully related with its comparatively low cost. But, high viscosity of this particular thermosetting polymer with inherent brittleness causes poor damage tolerance of its composites. Thus, unsaturated polyester

This is an open access journal, and articles are distributed under the terms of the Attribution 4.0 International (CC BY 4.0) License. This license lets others distribute, remix, tweak, and build upon your work, even commercially, as long as they credit the author for the original creation. You must give appropriate credit, provide a link to the license, and indicate if changes were made. 
has been blended with vinyl ester, to improve its performance as vinyl ester has a potential for enhancing mechanical and thermal properties of unsaturated polyester [16]. Vinyl ester is a well known and easily available high-performance thermosetting polymer with reactive double bonds and rigid epoxy structure. It is produced by the successful combination of epoxy with methacrylic acid with styrene as a cross linking agent for the polymerization reaction. Vinyl ester has a high mechanical, thermal properties and easy processing. It is commonly used in industrial applications such as laminating resin, composites, coating and adhesive.

The important contribution of this article is to study the inimitable characteristics of interaction of CS- $g$-MWCNTs with UPE/VE blend through van der Waals force of attraction as well as hydrogen bonding. The nanocomposites specimens fabricated at a low cost evidenced high mechanical strength, good stability by making them suitable for applications in the manufacturing of components for various thermal and electrical applications. Improved properties of this new fabricated multiphase composite make it a high quality promising candidate as a thermal interface material with capability to face the requirement of modern scenario for various applications.

\section{EXPERIMENTAL}

MWCNTs of $>98 \%$ carbon basis, diameter and length between 5-20 $\mathrm{nm}$ and 1-10 $\mu \mathrm{m}$ [O.D $\times$ I.D $\times$ Length $=10-30$ $\mathrm{nm} \times 0-10 \mathrm{~nm} \times 1-10 \mu \mathrm{m}]$ was supplied by Sigma Aldrich, USA. Chitosan $(80 \%$ deacetylated, MW $=100 \mathrm{KDa})$ and dicumyl peroxide (DCP) were purchased from Sigma Aldrich. UPE/VE blend was synthesized by using a reported method. All chemicals and solvents were used without any purification.

Chitosan functionalization of MWCNTs (CS- $g$-MWCNTs): Initially, chitosan was completely deacetylated in presence of $50 \% \mathrm{NaOH}$ solution with continuous stirring for $5 \mathrm{~h}$ at $80^{\circ} \mathrm{C}$ under a $\mathrm{N}_{2}$ atmosphere.

The product was filtered, washed with methanol and dried in oven repeatedly for 3 times. Finally, the MWCNTs and completely deacetylated chitosan (1:10) were added to $30 \mathrm{~mL}$ of anhydrous dimethyl formamide solution. The mixture was stirred at $120{ }^{\circ} \mathrm{C}$ for $96 \mathrm{~h}$ under a $\mathrm{N}_{2}$ atmosphere and then $0.02 \mathrm{~g}$ glutaraldehyde was introduced to the system for the cross linking of surface deposited chitosan. After reaction, the mixture was filtered through a $0.2 \mu \mathrm{m}$ microporous poly (ether sulfone) membrane, washed with $2 \%$ acetic acid to remove the adsorbed and uncrosslinked chitosan. Finally the product was dried to get a fluffy solid product. The whole scheme of preparation of CS- $g$-MWCNTs has been shown in Fig. 1.

Method of preparation of nanocomposite: The nanocomposites were prepared by dispersing varying content of CS- $g$-MWCNTs $(1,3,5$ wt \%) in the UPE/VE (50:50 wt \%) blend. They were mixed thoroughly by sonication for about $1 \mathrm{~h}$ at $60{ }^{\circ} \mathrm{C}$. Now, $5 \%$ cobalt naphthanate (w/w) accelerator and then $3 \% \operatorname{MEKP}(\mathrm{w} / \mathrm{w}$ ) Catalyst was mixed with the above mixture and stirred for $3 \mathrm{~h}$ at $100{ }^{\circ} \mathrm{C}$. When the catalyst was completely dissolved, the whole mixture was poured into the mould. At the beginning of fabrication, gel coat was uniformly brushed in to the finished side of male and female parts of the mould. Then the mould was subjected to hot-press (5 tons)

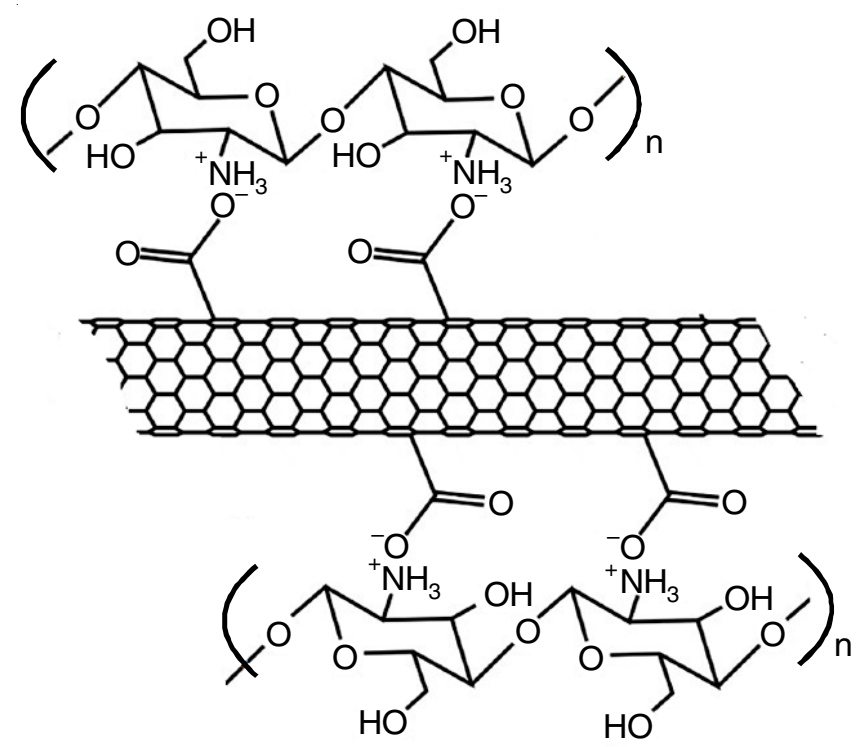

Fig. 1. Scheme of preparation of CS-g-MWCNTs

and the curing was carried out at $120^{\circ} \mathrm{C}$ in a convention oven for $2 \mathrm{~h}$.

Fourier transform infrared (FTIR) spectroscopy: FTIR spectra were collected using Thermo-Nicolate Model 400 instrument equipped with a controlled temperature cell (Model HT-32 heated demountable cell used with an Omega 9000-A temperature controller).

Scanning electron microscopy (SEM): SEM was performed to qualitatively examine the surface morphology of the nanocomposite for varying content of the functionalized nanofiller. The samples were gold coated and examined using a Philips 420T scanning electron microscope with a secondary electron detector, operating at $20 \mathrm{KV}$ in the SEM mode.

Mechanical testing: The tensile and flexural properties of different blends were studied by universal testing machine (HOUNSFIELD; H10KS) in accordance with ASTMD-638 and ASTMD-790. Impact strength was measured as per ASTM D256.All the results were taken as an average of four samples.

Viscoelastic properties [Dynamic mechanical analysis (DMA)]: For dynamic mechanical analysis, test specimens $(56 \mathrm{~mm} \times 13 \mathrm{~mm} \times 3 \mathrm{~mm})$ were cut from the center section of an ASTM Type I tensile bar. The dynamic mechanical properties like storage modulus and damping coefficient $(\tan \delta)$ were evaluated using a DMA tester (Model Q800).

Thermal properties measurement: Thermo gravimetric analysis (TGA) was performed on a Perkin-Elmer Series 7 thermal analyzer with a nitrogen atmosphere at a heating rate of $10{ }^{\circ} \mathrm{C} / \mathrm{min}$. The weight loss of the sample was measured as a function of temperature.

\section{RESULTS AND DISCUSSION}

Fourier transform infrared spectroscopy (FTIR): Fig. 2 shows the FTIR spectra of (a) MWCNTs and (b) CS- $g$ MWCNTs. The spectrum of MWCNTs shows an absorbance peak at around $1631 \mathrm{~cm}^{-1}$ ascribing to the $\mathrm{C}=\mathrm{O}_{\text {str }}$ group present on the surface of the MWCNTs. After the surface decoration with chitosan, a new strong absorbance at $1633.12 \mathrm{~cm}^{-1}$ is observed which indicated that MWCNTs reacted mainly with 


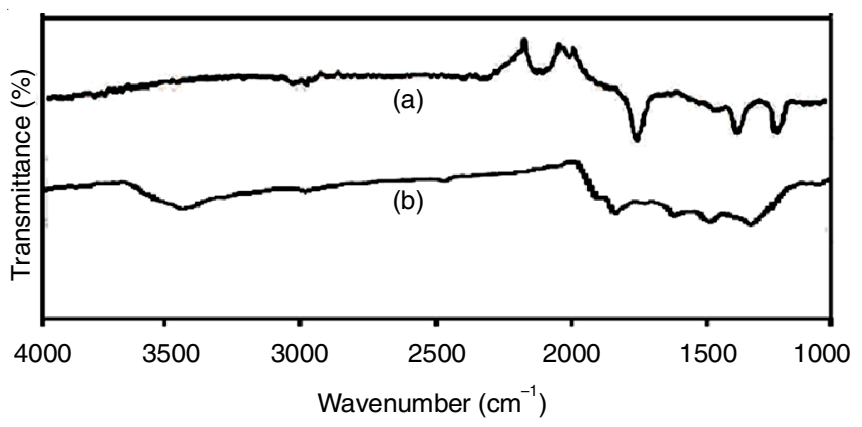

Fig. 2. FTIR spectra of (a) MWCNTs and (b) CS- $g$-MWCNTs

the $-\mathrm{NH}_{2}$ of chitosan and turned into $-\mathrm{NHCO}-$. This unique band frequency clearly indicates the formation of grafting between chitosan and MWCNTs.

Scanning electron microscopy (SEM): Fig. 3 shows the morphological structure analysis of (a) raw MWCNTs and (b) CS-g-MWCNTs. Raw MWCNTs shows smooth and regular morphology. In Fig. 3(b) the surface changed significantly with protrusion of chitosan after the surface modification of MWCNTs with chitosan. The bunch of MWCNTs get little bit expanded which can be attributed to the self-repelling tendency of the chitosan coatings. The MWCNTs possess a strong affinity to make bunches even after the surface modification which are bound collectively by the chitosan coatings.

The UPE/VE nanocomposite reinforced with $1 \mathrm{wt} \% \mathrm{CS}-$ $g$-MWCNTs [Fig. 4(a)] reveals low quantity of nanofillers dispersed in the matrix and unable to distribute evenly due to insufficient mass of the filler. $3 \mathrm{wt} \%$ nanocomposite depicts the homogeneity and good uniformity of the nanofiller as individual tubes in the matrix resulting in smooth and regular morphology given in Fig. 4(b). Better distribution of nanofiller enhances the properties and applicability of a composite. So this composition gave overall better properties. $5 \mathrm{wt} \%$ of nanofiller concentration [Fig. 4(c)] results in huge amount of clustered CS- $g$-MWCNTs due to the strong van der Waals force of attraction occurs due to poor dispersion and improper orientation of the nanofillers [17]. This reduces the interfacial attraction between the matrix and the nanofiller and lead to reduction in the properties of the blend based nanocomposites.

Mechanical testing: Table- 1 shows the tensile properties of the UPE/VE/CS- $g$-MWCNTs nanocomposites containing varying contents of functionalized MWCNTs. Nanofiller loading has a remarkable consequence on tensile strength of the nano composite. Strong interfacial bonding among the functionalized nanofiller and the polymer matrix due to better dispersion of the nano filler reduces the matrix-filler phase separation and enhances the mechanical properties of the nanocomposite. Tensile strength of the nanocomposite improves as nanofiller loading increases and attains the utmost value (56 MPa) at $3 \mathrm{wt} \%$ nanofiller content. At $1 \mathrm{wt} \%$ of CS- $g$-MWCNTs loading, the reinforcement effect is limited due to the low dispersion density of the filler. For $3 \mathrm{wt} \%$ loading, the distribution and dispersion started to progress as the nanofiller concentration becomes greater for acting as a support to resist maximum part of the load through effective interfacial stress transfer.
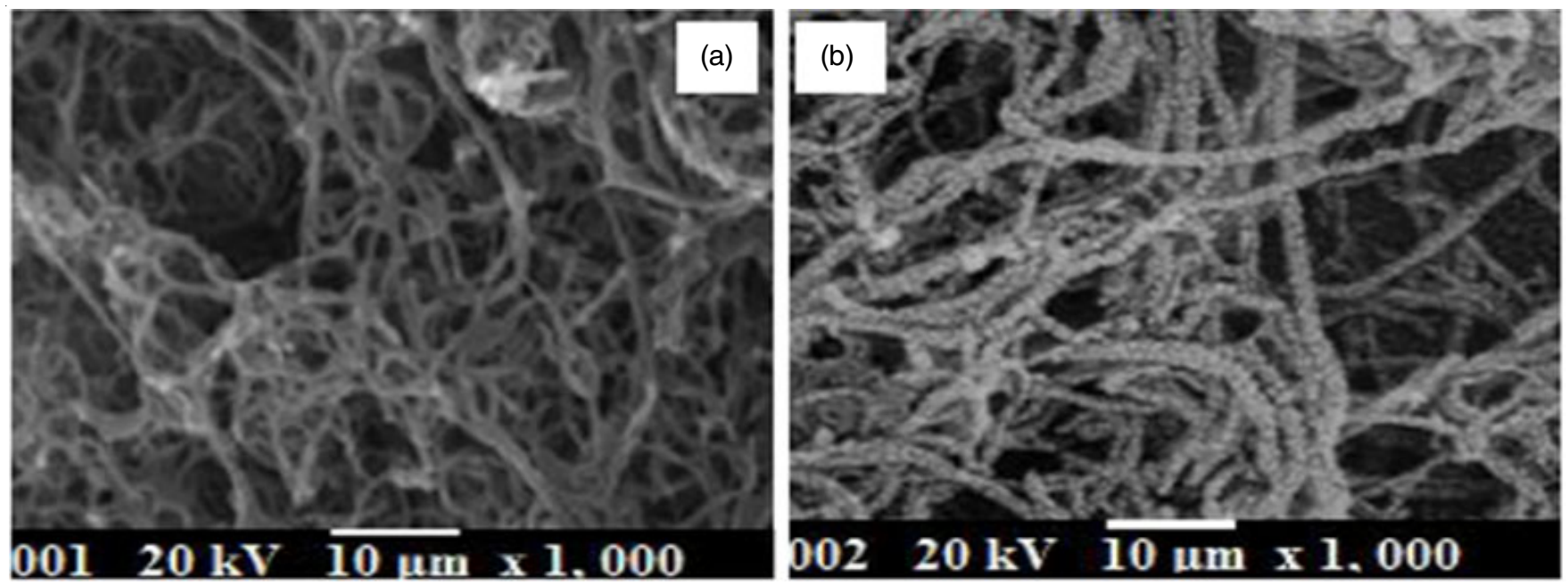

Fig. 3. SEM of (a) MWCNTs and (b) CS- $g$-MWCNTs
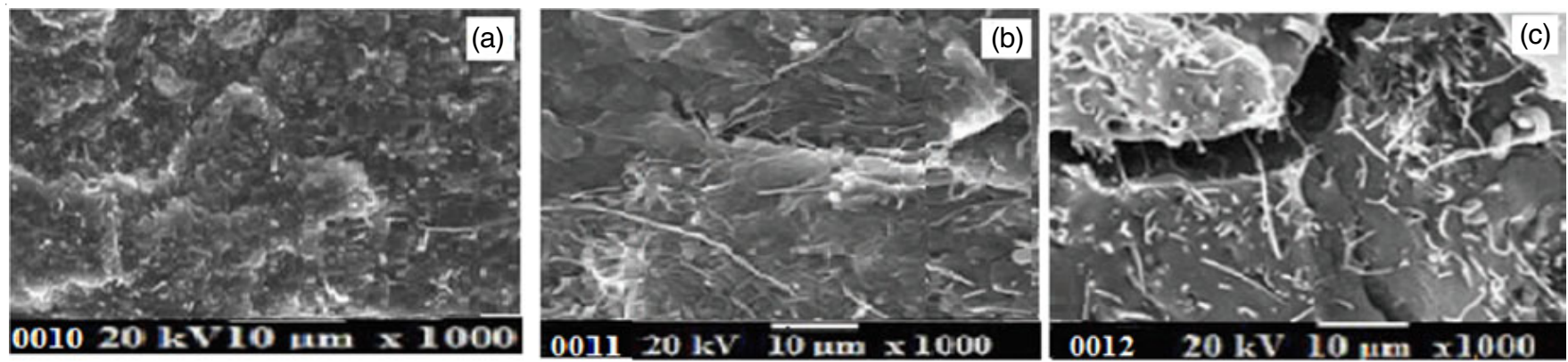

Fig. 4. SEM images of UPE/VE nanocomposites reinforced with (a) CS- $g$-MWCNTs (1 wt \%) (b) CS- $g$-MWCNTs (3 wt \%) (c) CS- $g$ MWCNTs (5 wt \%) 
TABLE-1

MECHANICAL PROPERTIES OF DIFFERENT TYPES OF NANOCOMPOSITES

\begin{tabular}{ccccccc}
\hline $\begin{array}{c}\text { Specimens (UPE/VE/CS- } g \text { - } \\
\text { MWCNTs loading) }(\mathrm{wt} \%)\end{array}$ & $\begin{array}{c}\text { Tensile } \\
\text { strength }(\mathrm{MP})\end{array}$ & $\begin{array}{c}\text { Tensile } \\
\text { modulus }\left(\mathrm{GP}_{\mathrm{a}}\right)\end{array}$ & $\begin{array}{c}\text { Bending } \\
\text { strength }\left(\mathrm{MP}_{\mathrm{a}}\right)\end{array}$ & $\begin{array}{c}\text { Bending } \\
\text { modulus }\left(\mathrm{GP}_{\mathrm{a}}\right)\end{array}$ & $\begin{array}{c}\text { Impact } \\
\text { strength }(\mathrm{J} / \mathrm{m})\end{array}$ & $\begin{array}{c}\text { Fracture } \\
\text { strain }(\%)\end{array}$ \\
\hline 0 & $34 \pm 1$ & $3.8 \pm 0.2$ & $44 \pm 2$ & $1.4 \pm 0.1$ & $48 \pm 3$ & $4.2 \pm 3$ \\
1 & $40 \pm 3$ & $3.9 \pm 0.3$ & $49 \pm 3$ & $2.2 \pm 0.2$ & $52 \pm 2$ & $3.71 \pm 1$ \\
3 & $56 \pm 2$ & $5.2 \pm 0.2$ & $53 \pm 4$ & $3.6 \pm 0.1$ & $66 \pm 4$ & $2.5 \pm 2$ \\
5 & $41 \pm 2$ & $4.1 \pm 0.2$ & $40 \pm 3$ & $2.4 \pm 0.1$ & $57 \pm 4$ & $3.8 \pm 3$ \\
\hline
\end{tabular}

Therefore, the tensile results for $3 \mathrm{wt} \% \mathrm{CS}$ - $g$-MWCNTs filled nanocomposites showed better strength compared to $1 \mathrm{wt} \%$ nanofiller loading. Further increase of nanofiller loading, decreases the tensile strength due to the aggregation of the nanofiller at high concentration. Thus, when the nanocomposite is under load, the nanomaterials in the cluster may produce a high stress concentration and cause premature failure [18]. Tensile modulus is a common method to measure the stiffness of a material [19]. If tensile modulus enhances then the material was considered as rigid. Table-1 shows tensile modulus of the same nanocomposites. Unsaturated polyester matrix exhibited a tensile modulus value of $3.8 \mathrm{GP}_{\mathrm{a}}$ which increases to $5.2 \mathrm{GP}_{\mathrm{a}}$ on addition of $3 \mathrm{wt} \%$ of UPE/VE/CS- $g$-MWCNTs. It may be due to the above said reasons.

The result of functionalized nanofiller loading on the bending strength, bending modulus and impact strength of UPE/VE (50:50 w/w) nano composite are presented in Table-1.

The results suggested an increase in the properties at the nano filler concentration up to $3 \mathrm{wt} \%$ due to better reinforcement effect of the nanofiller. This tendency confirms that interfacial interactions between the polymer and the nanofiller play vital role for determining the reinforcement efficiency in the nanocomposite. All these values reduce with increasing the nanofiller content up to $5 \mathrm{wt} \%$ owing to the formation of big clusters by the aggregation of the graphite flakes. This leads to non-uniform dispersion in the polymer matrix and decreases the required properties. Actually proper distribution of the properly functionalized nanofiller reduces the chain flexibility of the blend by improving the cross linking density and enhances the stiffness.

At 3 wt $\%$ of functionalized MWCNTs nanofiller reinforcement lowest value of fracture strain is observed as the brittleness of the nano composite gradually decreased with the addition of this nanofiller. Further addition of nanofiller increases the value as the brittleness increases. Table- 1 shows the fracture strain $\%$ of the nanocomposite with varying content of nanofiller.

Viscoelastic properties: Generally, DMA is used to determine the storage modulus $\left(\mathrm{E}^{\prime}\right)$ that is associated with the ability of the material to return or store mechanical energy and $\tan \delta$ which helps to predict the structural behaviour of nanocomposites based on their glass transition temperatures. Fig. 5 shows the variation of storage modulus and loss modulus with temperature for the nanocomposites with varying content of CS- $g$-MWCNTs nanofiller loading. The materials showed substantial improvements in the storage modulus with an instantaneous increase in the glass transition temperatures of the nanocomposites with enhancing the nanofiller loading. The improvement in dynamic-mechanical properties of nanocomposites may be elucidated in terms of superior interfacial properties and controlled thermal motions of the CS-g-MWCNTs wrapped by chitosan. The materials presented improved storage modulus with raise in nanofiller content. As temperature enhanced, all the nanocomposites showed a rapid fall in storage modulus and the glass transition temperature $\left(\mathrm{T}_{\mathrm{g}}\right)$ that is interrelated to the material transition from a glassy state to a rubbery state. At higher graphite, content up to $3 \mathrm{wt} \%$ an elevated storage modulus was observed above $\mathrm{T}_{\mathrm{g}}$ or in the rubbery region. At this concentration, the nanocomposite showed highest $\mathrm{T}_{\mathrm{g}}$ of $147{ }^{\circ} \mathrm{C}$ and about $28 \%$ and $31 \%$ higher storage modulus respectively than $1 \mathrm{wt} \%$ and $5 \mathrm{wt} \%$ nanocomposite. At $3 \mathrm{wt} \%$, the values of storage modulus attain maximum value with diminished $\tan \delta$ value because of suitable orientation of the nanoparticles and strong interfacial interactions that reduces the movement of the molecular chain at the interface. Again
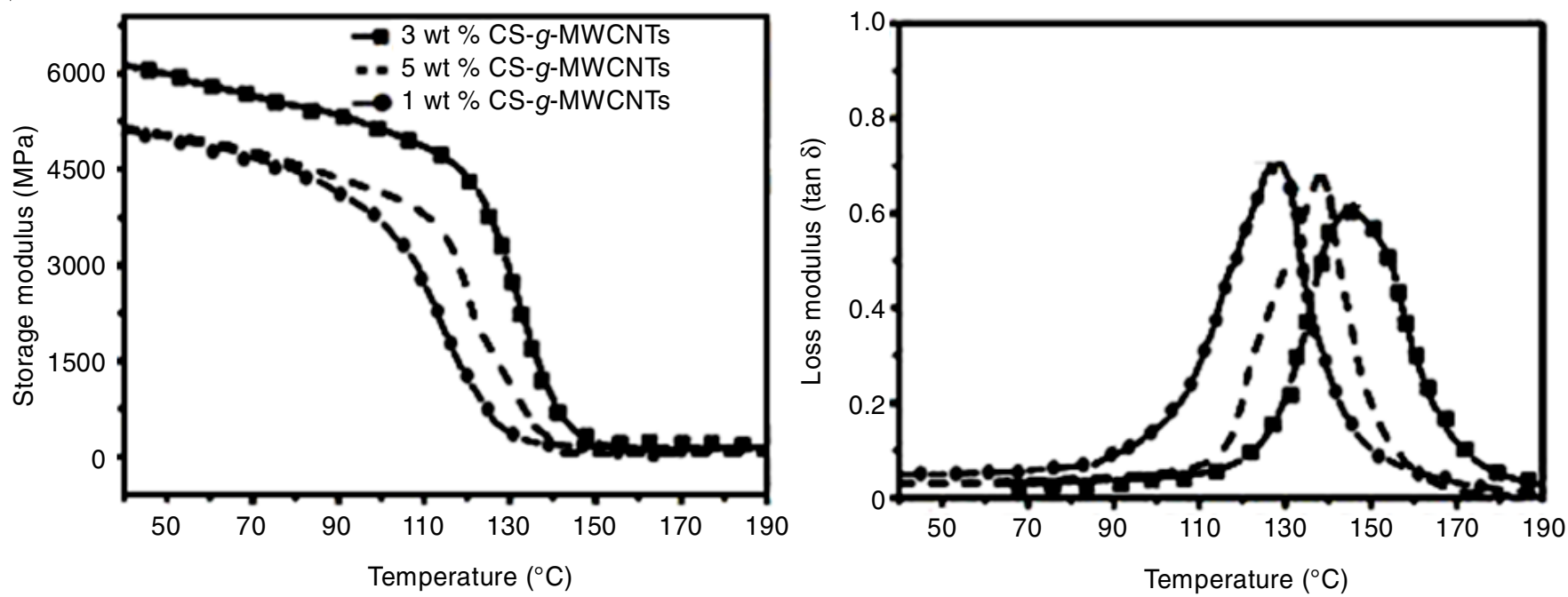

Fig. 5. Dynamic mechanical spectra of different types of nanocomposites 
due to compact phase arrangement the free space available is too small and maximum energy is required for the polymer molecules to move, thereby reducing damping [20,21]. However, at $5 \mathrm{wt} \%$ nanofiller concentration, there is increased chances of vacant space availability only due to the particle agglomeration that leading to low energy absorption with slightly decreased cross-linking density and increased polymeric chain flexibility by the polymer molecules. Thus, it exhibits low storage modulus with increased damping coefficient. So, here the storage modulus value decreases and damping coefficient value increases.

Thermal stability: Thermal stability of the prepared nanomaterials was determined by thermo gravimetric analysis. Fig. 6 depicts that an increase in nanofiller loading increases the thermal stability of VE/UPE blend. The thermogram indicates only one phase of thermal decomposition platform, indicating a one step process. The weight loss under $150{ }^{\circ} \mathrm{C}$ was due to the loss of water molecules [22] and beyond $150{ }^{\circ} \mathrm{C}$ referred to the loss of bonded water molecule present in the nanocomposite polymeric chain. For the chitosan grafted carbon nanotube reinforced nanocomposites, the thermal stability increases may be due to the increase in crosslink density and improved polymer filler interaction. It is only due to the successful interaction of chitosan on the surface of the carbon nanotube.

Here $5 \%$ weight loss for the neat resin is $212{ }^{\circ} \mathrm{C}$ whereas 1,2 and 3 wt $\%$ graphite has only $1.5 \%$ of total weight loss up to $800{ }^{\circ} \mathrm{C}$. However, both the neat unsaturated polyester and the nanocomposites show thermal degradation at lower temperature. Table- 2 represents the TGA values of unsaturated polyester and the UPE/graphite nanocomposite indicate that thermal stability of the matrix was increased by the incorporation of graphite particles. The nanocomposites also have higher char content or decreased weight loss. Pure unsaturated polyester shows a char content of $9 \%$ whereas the 1 wt $\%, 3$ wt $\%$ and $5 \mathrm{wt} \%$ nanofiller filled nanocomposites show about 32,48 and $25 \%$ of char yield respectively. This increased thermal stability may be due to the better cross linking and compatibility between the matrix and the nanofiller that create a convoluted path in the composites to restrict the diffusion of the volatile decomposition products. The presence of these nanofiller with optimum concentration of $2 \mathrm{wt} \%$ results compactly packed structure without any cracks and voids and induces thermal resistance. In addition the $\mathrm{T}_{\max }$ shows higher value by confirming higher thermal stability at this particular concentration. But incorporation of $5 \mathrm{wt} \%$ nanofiller into the blend matrix showed about $10 \%$ reduced thermal decomposition temperature than its corresponding $3 \mathrm{wt} \%$ graphite filled nanocomposite due to aggregation of fillers and poor surface characteristics resulting in thermal instability.

\section{Conclusion}

The distinctiveness of this work includes the use of CS$g$-MWCNTs as nanofiller in varying proportions into VE/UPE matrix. The overall results showed from SEM that they have compatibility. The produced material has received much concentration due to their prospective to gain properties superior to conventional engineering materials. The studies revealed significant improvement in morphological, mechanical, viscoelastic and thermal properties. which is very important for various engineering and nanoelectronics applications. The excellent combination of cost effectiveness, light weight and unique properties of functionalized nanocomposite has drawn attention to the development of multifunctional polymer based nanocomposites in recent years. Formation of effective conductive network slowed the growth of micro cracks and enhances better
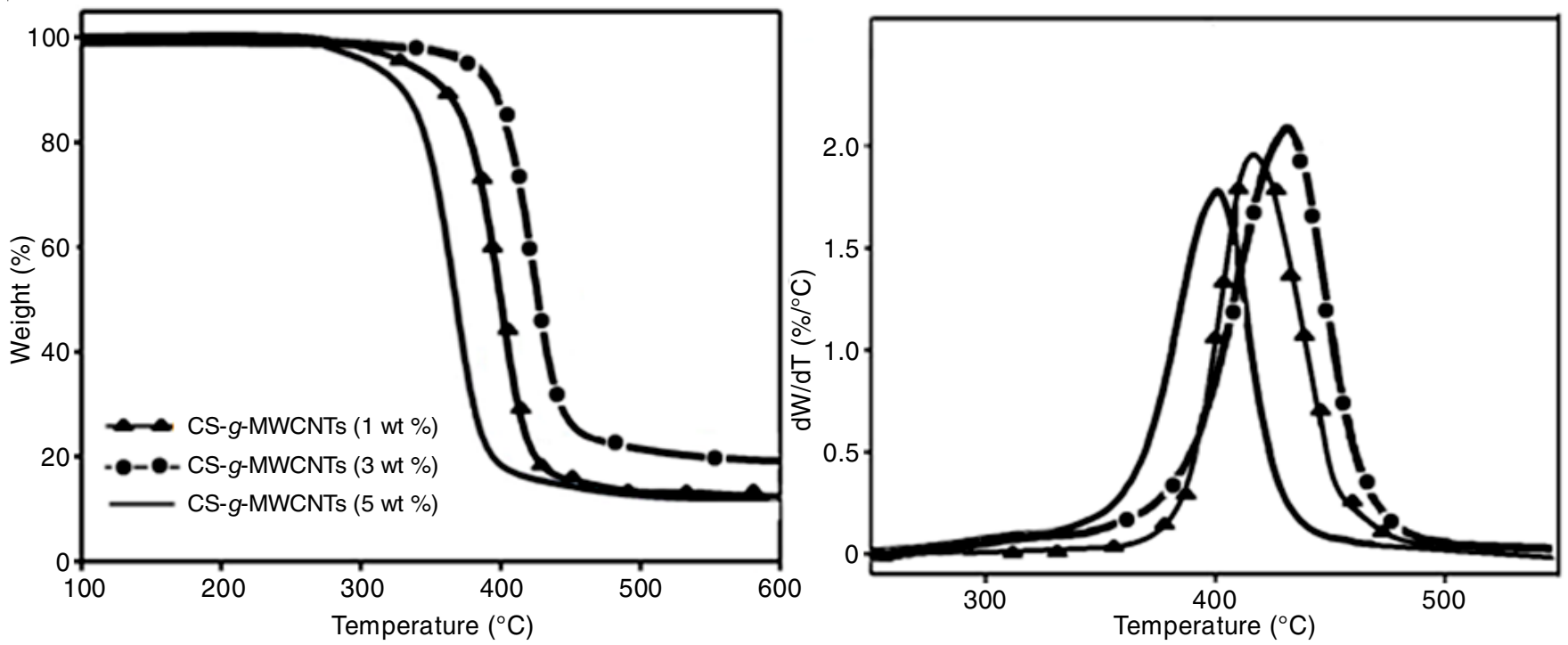

Fig. 6. Thermo gravimetric analysis of different types of nanocomposites

TABLE-2

THERMAL PROPERTIES OF DIFFERENT TYPES OF NANOCOMPOSITES

\begin{tabular}{lccccc}
\multicolumn{1}{c}{ Nano composites } & Onset $\left({ }^{\circ} \mathrm{C}\right)$ & $\mathrm{T}_{5 \%}\left({ }^{\circ} \mathrm{C}\right)$ & $\mathrm{T}_{50 \%}\left({ }^{\circ} \mathrm{C}\right)$ & Endset $\left({ }^{\circ} \mathrm{C}\right)$ & Char yield $(\%)$ \\
\hline 1 wt \%CS- $g$-MWCNTs & 405 & 343 & 432 & 473 & 32.16 \\
3 wt \%CS- $g$-MWCNTs & 421 & 395 & 454 & 498 & 48.29 \\
5 Wm,k,L3t \% CS- $g$-MWCNTs & 413 & 311 & 423 & 452 & 25.37 \\
\hline
\end{tabular}


matrix-filler interaction with homogeneous distribution of filler in the matrix from efficient hybrid network in optimum concentration of 3 wt \% nanofiller. This is the reason behind these enhanced properties with special importance to transport properties. The successful increase in $\mathrm{T}_{\mathrm{g}}$ for $3 \mathrm{wt} \%$ of this unique nanofiller content proved the superior confinement effect of the nanofiller. The optimum properties are achieved at 3 wt $\%$ because at higher nanofiller content of $5 \mathrm{wt} \%$ the agglomeration of fillers has occurred that work as stress concentrators and reduce the overall properties. Again, increment of cross linking density and crystallinity of the nanocomposite than the pristine matrix enhances their potential for application. Thus, the above nanocomposite could be a better candidate for a variety of structural applications with the ability of advanced functioning.

\section{ACKNOWLEDGEMENTS}

The assistance provided by IIT, Kharagpur and NIT, Rourkela, India during the completion of the experimental works are greatly acknowledged.

\section{CONFLICT OF INTEREST}

The authors declare that there is no conflict of interests regarding the publication of this article.

\section{REFERENCES}

1. D.R. Paul and L.M. Robeson, Polym. J., 49, 3187 (2008); https://doi.org/10.1016/j.polymer.2008.04.017.

2. M. Naffakh, A.M. Diez-Pascual, C. Marco, G. Ellis and M.A. GomezFatou, Prog. Polym. Sci., 38, 1163 (2013); https://doi.org/10.1016/j.progpolymsci.2013.04.001.

3. S. Iijima, Nature, 354, 56 (1991); https://doi.org/10.1038/354056a0.

4. S.J. Tans, M.H. Devoret, H. Dai, A. Thess, R.E. Smalley, L.J. Geerligs and C. Dekker, Nature, 386, 474 (1997); https://doi.org/10.1038/386474a0.
5. M.M.J. Treacy, T.W. Ebbesen and J.M. Gibson, Nature, 381, 678 (1996); https://doi.org/10.1038/381678a0.

6. P.R. Austin, C.J. Brine, J.E. Castle and J.P. Zikakis, Science, 212, 749 (1981); https://doi.org/10.1126/science.7221561.

7. H.K. No and S.P. Meyers, J. Agric. Food Chem., 37, 580 (1989); https://doi.org/10.1021/jf00087a002.

8. J. Ruiz-Herrera, The Distribution and Quantitative Importance of Chitin in Fungi, In Proceedings of The First International Conference on Chitin/ Chitosan, Cambridge (1978).

9. M.T. Yen, J.H. Yang and J.L. Mau, Carbohydr. Polym., 75, 15 (2009); https://doi.org/10.1016/j.carbpol.2008.06.006.

10. C.R. Allan and L.A. Hadwiger, Exp. Mycol., 3, 285 (1979); https://doi.org/10.1016/S0147-5975(79)80054-7.

11. A. Wojtasz-Pajek, A. Ramisz, M. Malesa-Ciecwierz and A. Balicka-Ramisz, Advances in Chitin Science, European Chitin Society, International Conference, pp. 440-447 (1996).

12. M.N.V. Ravi Kumar, React. Funct. Polym., 46, 1 (2000); https://doi.org/10.1016/S1381-5148(00)00038-9.

13. M. Rinaudo, Prog. Polym. Sci., 31, 603 (2006); https://doi.org/10.1016/j.progpolymsci.2006.06.001.

14. C.G. Liu, K.G.H. Desai, X.G. Chen and H.J. Park, J. Agric. Food Chem., 53, 1728 (2005); https://doi.org/10.1021/jf040304v.

15. I. Goodman and J.A. Rhys, Saturated Polymers, Iliffe: London (1965).

16. A.N. Fraga, V.A. Alvarez, A. Vazquez and O. de la Osa, J. Compos. Mater, 37, 1553 (2003); https://doi.org/10.1177/0021998303029421.

17. D. Galpaya, M. Wang, M. Liu, N. Motta, E. Waclawik and C. Yan, Graphene, 1, 30 (2012); https://doi.org/10.4236/graphene.2012.12005.

18. C.L. Wu, M.Q. Zhang, M.Z. Rong and K. Friedrich, Compos. Sci. Technol., 62, 1327 (2002); https://doi.org/10.1016/S0266-3538(02)00079-9.

19. Z. Wang, J.K. Nelson, H. Hillborg, S. Zhao and L.S. Schadler, Compos. Sci. Technol., 76, 29 (2013); https://doi.org/10.1016/j.compscitech.2012.12.014.

20. O. Becker, R. Varley and G. Simon, Polym. J., 43, 4365 (2002); https://doi.org/10.1016/S0032-3861(02)00269-0.

21. T. Agag, T. Koga and T. Takeichi, Polym. J., 42, 3399 (2001); https://doi.org/10.1016/S0032-3861(00)00824-7.

22. S. Sinha, S. Bhadra and D. Khastgir, J. Appl. Polym. Sci., 112, 3135 (2009); https://doi.org/10.1002/app.29708. 